\title{
New Environmental Indicator to Support Decision Making
}

\section{Edgar Ricardo $\mathbf{M V}^{1^{*}}$ and Pouey $\mathbf{N}^{2}$}

${ }^{1}$ Universidad Gran Colombia, Bogota, Colombia

${ }^{2}$ Universidad Nacional de Rosario, Argentina

"Corresponding author: Edgar Ricardo MV, Universidad Gran Colombia, Bogotá, Colombia, Tel: 2459553-3406474; E-mail: edgar.monroy@ugc.edu.co Received date: Dec 05, 2016; Accepted date: Jan 28, 2017; Published date: Jan 31, 2017

Copyright: (c) 2017 Edgar Ricardo MV, et al. This is an open-access article distributed under the terms of the Creative Commons Attribution License, which permits unrestricted use, distribution, and reproduction in any medium, provided the original author and source are credited.

\begin{abstract}
The environmental management and land use planning, turns out to be a difficult issue for all governmental authorities. Monroy Ph.D., in his doctoral work called Systemic Model for Environmental Impact Assessment at a River Basin Level, proposed a methodology to quantitatively assess the environmental impact at a river basin level. In the same work proposed an indicator called EVI (Environmental Value Indicator, standing for IVA in Spanish), which includes the result of environmental impact value with other macroeconomic variables, with the support of Fuzzy Logic. It is important to note that the estimated environmental impact at the Cuenca level is quantitative, and the $\mathrm{EVI}$ is an important and innovative contribution in environmental assessment and management. For the ablation of this methodology was worked as a case study of the Garagoa River Basin in Colombia. This work supports a better decision making about its use and environmental management.
\end{abstract}

Keywords: Environmental Value indicator (EVI); Environmental impact assessment; Macroeconomic; Gross Domestic Product (GDP)

\section{Introduction}

The objective of this study is to create a methodology that estimates the economic cost of the environmental impact in a basin, resulting in a new macroeconomic indicator of environmental type denominated: Environmental Value Indicator (EVI).

Inflation, gross domestic product, the devaluation, the gini are some economic variables that quickly, give us all a general idea of the state of any region in socioeconomic terms, without having to be experts in this topic. Now, similarly, the author wanted to formulate an indicator called EVI (standing for IVA in Spanish), which especially enables the environmental manager, to have an order of magnitude of the cost of the environmental impact associated with a river basin $[1,2]$.

To achieve this indicator was first necessary to have a mathematical value associated with this environmental impact, which the author called IF (Standing for FIC in Spanish), impact factor, and in this work, is taken as a starting point or true fact, to the extent that the focus is on the dissertation of how the economic variables that converge in a basin with the environmental impact IF are joined together through the methodology of Fuzzy Logic in a single macro-indicator that called EVI [1].

It is clear from a scientific point of view; the understanding of some physical processes is based on human reasoning [3]. This reasoning can be exploited for structuring models and the ability to encapsulate it in solving complex problems and intractable is the criterion by which the effectiveness of the heuristics and met heuristics models [4]. Perhaps the accuracy of these models cannot fully solve the problem, however, it could be a strategy for decision making on the analysis of environmental problems and especially for the assessment of the environmental damage of river basin systems.

\section{Materials and Methods}

Preamble The starting point involves previous knowledge about the value of the environmental impact of a basin, which in this case corresponds to the Garagoa of the river, shown on Map 3.1, built from geographic information systems GIS, and that has been called ISOFIC, i.e., curves of equal environmental impact framed in the basin of study.

Secondly, the purpose of this research stage is the identification of a metaheuristic model, implementing the tool "fuzzy logic" to allow the integration of the estimated result by the "Environmental Impact Factor" with some socioeconomic variables, leading to a final analysis of the "Environmental Value Indicator (EVI)" [5]. The bond of the variables described above, is not tractable and therefore, it is suggested the application of a fuzzy logic model that allows to glimpse the behavior of parametric interaction. When considering the use of fuzzy logic to any engineering problem, the degree of uncertainty in the response to the problem must be weighed, indeed, not only inaccurate data dictates the quality of response but also the low tractability of the problem [3].

Human activities are generating ecosystems intervention and damage. However, the intensity and impact are different according to several parameters that tend to be directly associated with economic and social activity. The communities in general, are characterized by several indicators that reflect their condition. In the case of the economy, changes in the situation may occur by multiple factors, which ultimately are showing their direct or indirect relationship with their environment. Not all societies and economic situations have the same damage to the environment. The degree of association and combination of variables in relation to the construction of the environmental impact value will be subsequently argued.

The socioeconomic variables that were selected (three of them) take into account its primacy in assessing the economic state of a society, these are: The Gross Domestic Product (GDP), population growth rate, and the GINI coefficient. 
Page 2 of 5

The indicator of economic growth is the result of increased aggregate of a country by its economic agents over time, usually one year production, expressed through the GDP. There is a great partnership between GDP growth and the economic impact on the environment. It is assumed that further growth of the productive system in any of its components, generates a great impact on environmental degradation. The higher the economic growth, the greater the environmental damage generated by economic agents (Figure 1) [6].

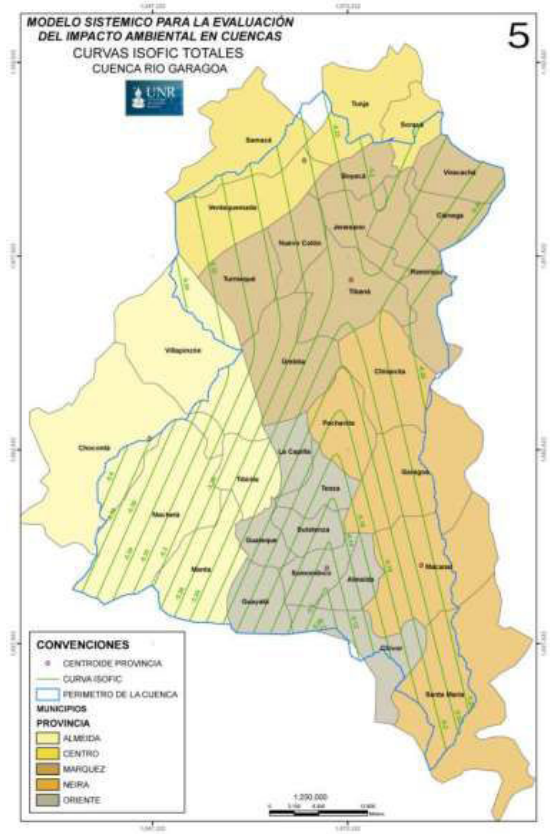

Figure 1: Isofic curves.

The rate of population growth, in a demographic point of view, refers to demographic shifts of a given volume of people, from one residence to another. The population change (positive or negative growth) experienced by the population size is the result of births and deaths (natural increase) and the net contribution of migration. The growth rate is expressed as the percentage of population changes from one period to another.

The environmental relationship with the variable is possible in the extent of the existence of a greater number of people living in the territory, an increase also occurs in the demand for environmental goods and services, from the appropriation of the biomass for energetic purposes, to the dump of wastes into the basin. The higher the population growth, the greater the environmental degradation in the territory [7].

The Gini coefficient is a measure of equity, which shows the percentage distribution of a variable is in the population. It is usually associated to the welfare of the population in relation to their involvement with the income. Zero corresponds to a perfectly equal income distribution (everyone has the same income) and 1 to a perfectly unequal distribution (one person has all the income and the rest has nothing). In other words, the closer to 0 the Gini index is a more equitable society. The Gini index is the Gini coefficient expressed as a percentage and is equal to the GINI coefficient multiplied by 10 [8]

The relationship between GINI coefficients with the environmental component is associated so that an increase in the level of poverty or income inequality within a population, generate a greater environmental damage. The poorer a society is, the greater the environmental conflicts generated due to their precarious income, the level of education and other related variables $[9,10]$.

\section{Results and Conclusions}

For analysis Environmental Value Indicator (EVI) three economic variables of interest and the Impact Factor (IF) has established as the functional elements of the fuzzy inference system. Membership functions selected for the study are trapezoid and/or triangular, due to its simple and easy defined structure.

For the rate of GDP growth, the universe of discourse is defined between $-1 \%$ and $15 \%$, and consists of three membership functions (e.g., Low, Medium, High) where the indicators are characterized as follows: i) "low" between $1 \%$ and 3\%, ii) "Medium" between $2.5 \%$ and $6 \%$, and iii) "high" between 5\% and 15\% (Figure 2).

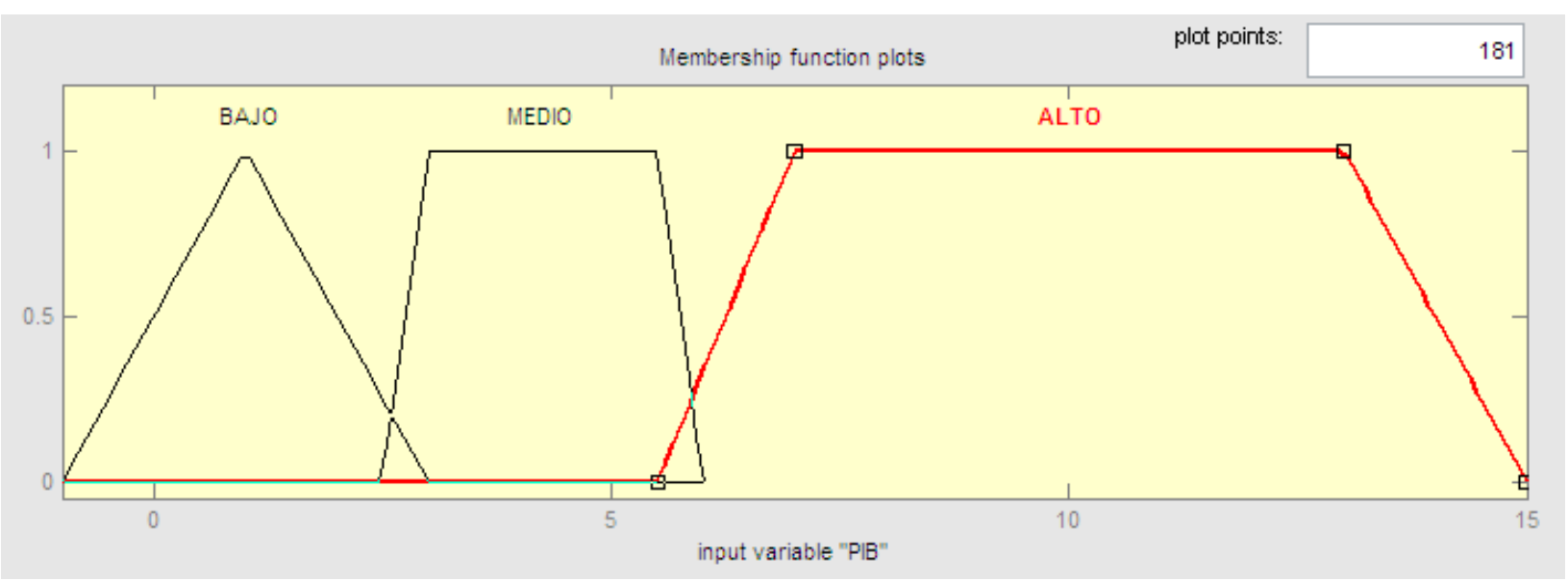

Figure 2: Membership functions of the fuzzy set defined by the GDP. 
Citation: Edgar Ricardo MV, Pouey N (2017) New Environmental Indicator to Support Decision Making. J Climatol Weather Forecasting 5: 188.

Page 3 of 5

For the Rate of Population Growth (RPG) the universe of discourse is defined between $-1 \%$ and $15 \%$, and consists of three membership functions (e.g., Low, Medium, High) where the indicators are characterized as follows: i) "low" between $1 \%$ and $2 \%$, ii) "Medium" between $1.5 \%$ and 5\%, and iii) "High" between $4.5 \%$ and 15\% (Figure 3).

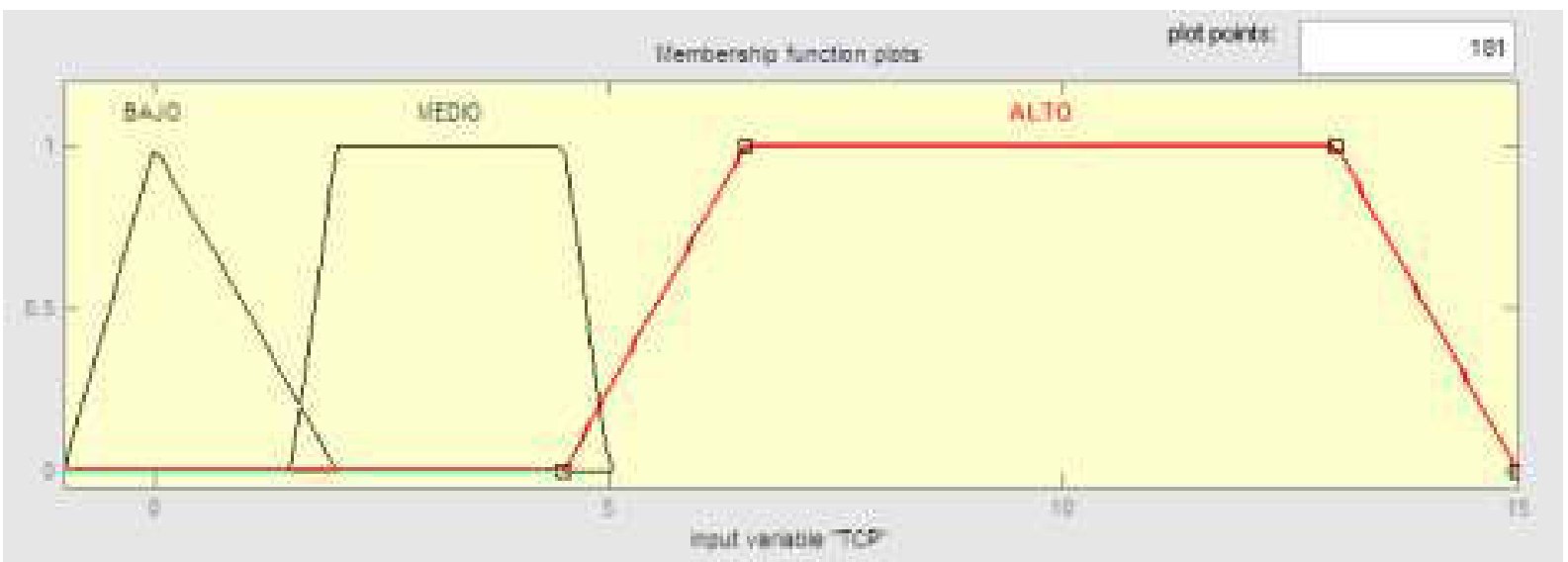

Figure 3: Membership functions of the fuzzy set defined by the RPG.

For the Gini index universe of discourse is defined between 0 and 1 , and consists of three membership functions (e.g., Low, Medium, High) where the indicators are characterized as follows: "low" between 0 and

0.15 , ii) "medium" between 0.10 and 0.45 , and iii) "high" from 0.42 to 1 (Figure 4).

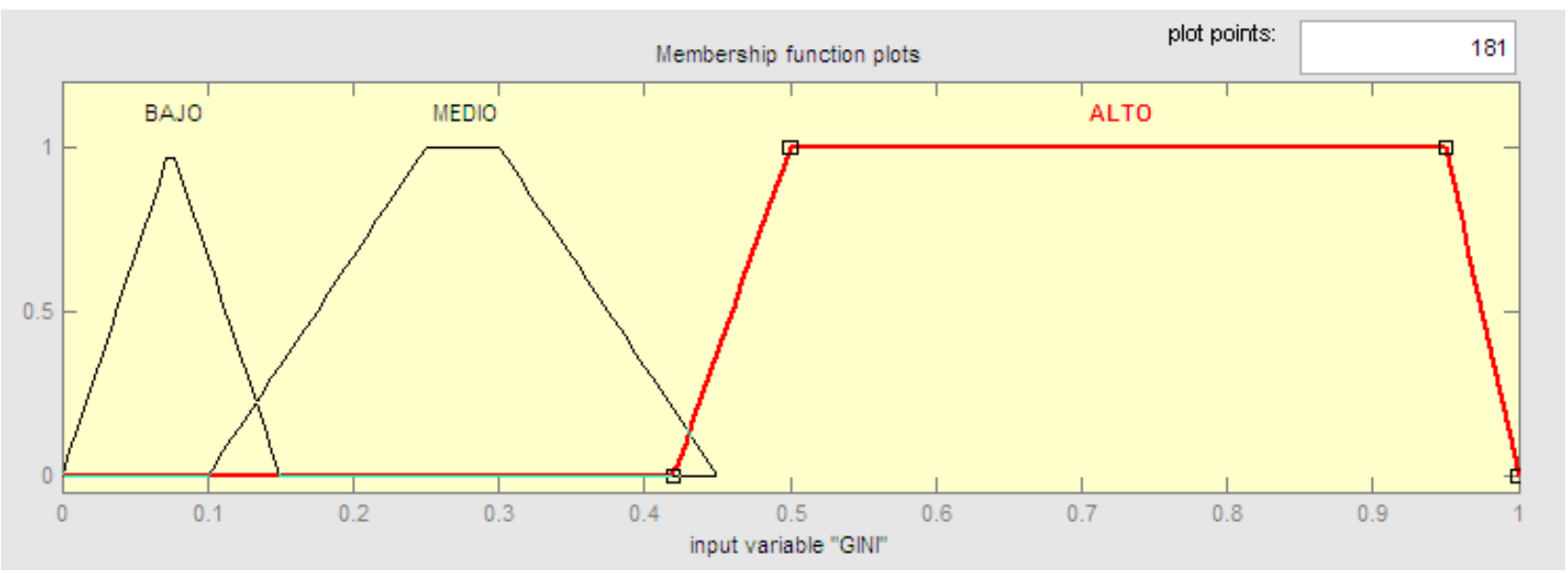

Figure 4: Memebership functions of the fuzzy set defined by the GINI index.

For the Impact Factor (IF) the universe of discourse is defined between -12 and 12 , and consists of six membership functions where the indicators are characterized as follows:

i) "high negative" between -12 and -9 ,

ii) "Medium negative " from -9 to -5 ,

iii) "Low negative" between -5 and 0 ,

iv) "low positive" between 0 and 5 ,

v) "medium positive" between 5 and 9, and vi) "high positive" between 9 and 12 (Figure 5).
For the system output, the Environmental Value Indicator, the universe of discourse is defined between 0 and 0.4 , and consists of five membership functions where the indicators are characterized as follows:

i) "low" between 0 and 0.05 ;

ii) "medium low" between 0.045 and 0.185 ,

iii) "medium" between 0.18 and 0.24 ,

iv) "medium high" between 0.225 and 0.31 , and v) "high" between 0.3 and 0.4 (Figure 6). 
Citation: Edgar Ricardo MV, Pouey N (2017) New Environmental Indicator to Support Decision Making. J Climatol Weather Forecasting 5: 188.

Page 4 of 5

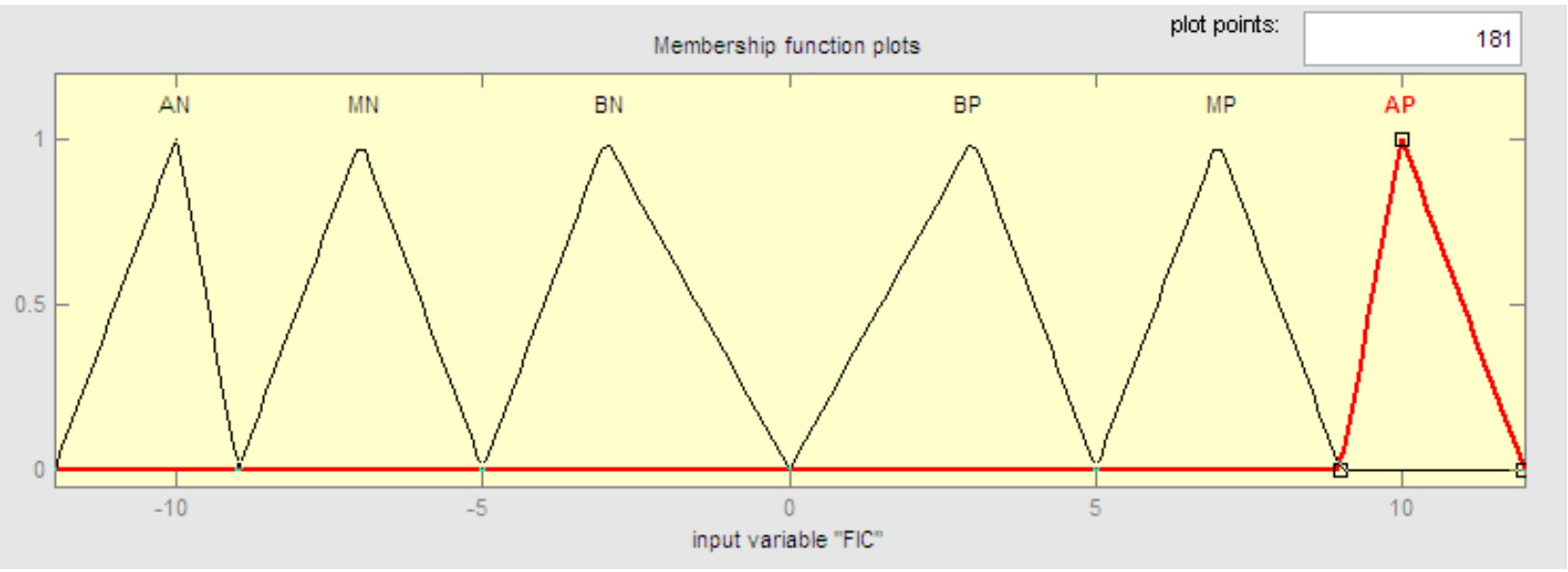

Figure 5: Memebership functions of the fuzzy set defined by the IF.

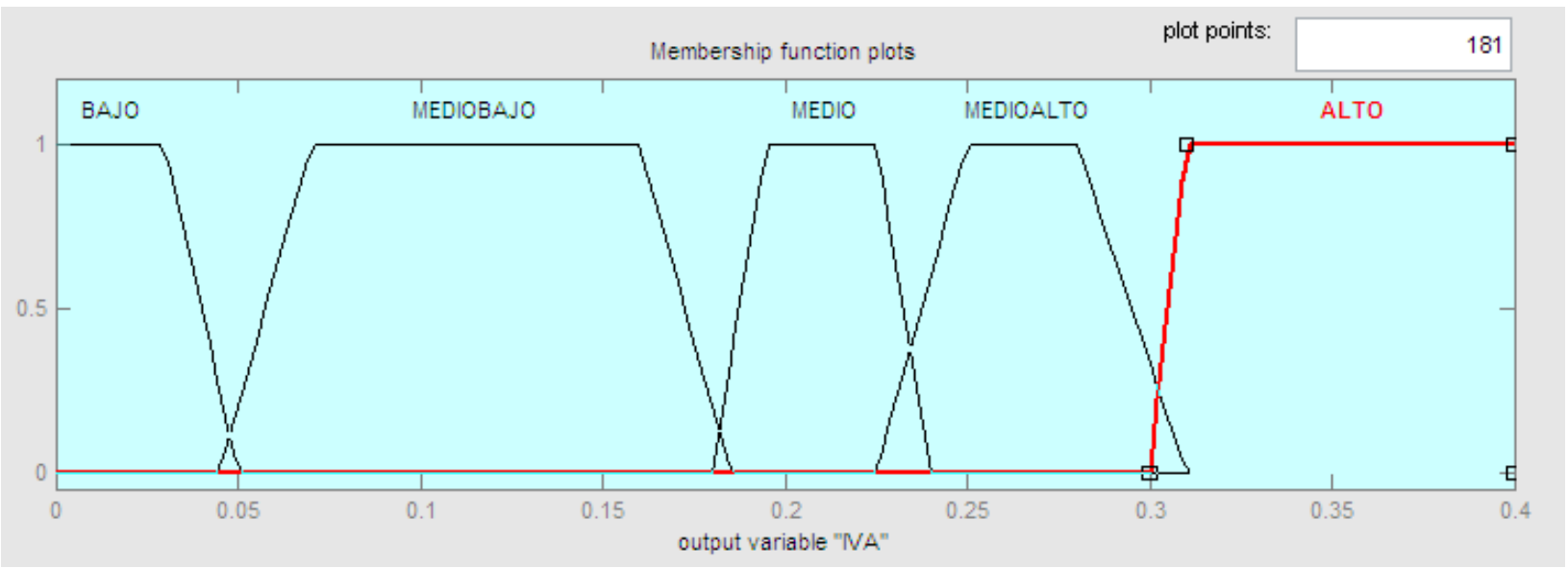

Figure 6: Memebership functions of the output fuzzy set defined by the EVI.

In the analysis of EVI 23 rules has been set, and in Figure 3. It is possible to observe the result of the aggregation process for the 23 rules defined in the EVI analysis, which were processed in the fuzzy logic "Toolbox" of "MATLAB version 7.5" (Figure 7; Table 1).

The greater the economic and population growth and the higher levels of poverty, the greater the environmental conflicts; if the variables behavior is the other way around, the situation will be more favorable. However, each country and situation, reflect different results, although the ultimate goal is not oriented to economic and social condition of the country, but to the environmental degradation of the illustrated and measuring ecosystem.

The IVAFIC model in its second phase, from fuzzy logic model develop, provides a simple exercise to estimate an economic environmental indicator called: Environmental Value Indicator (EVI), which for practical purposes, infers the cost of the environmental condition a basin.

The EVI model in its second phase, provides a tool indicator-type (EVI) that associates economic and environmental variables, in this case the Impact Factor Corrected IFC, and for the executive or legislative authority, is of great importance for the understanding of the economic environmental behavior of a river basin and its resulting decision-making, either through agreements, ordinances, laws, or at local levels, river basin management and protection plans.

This methodology is currently used in another basin as a postdoctoral research project with the aim of limiting new scenarios and variables, which is expected to narrow results with greater certainty. 

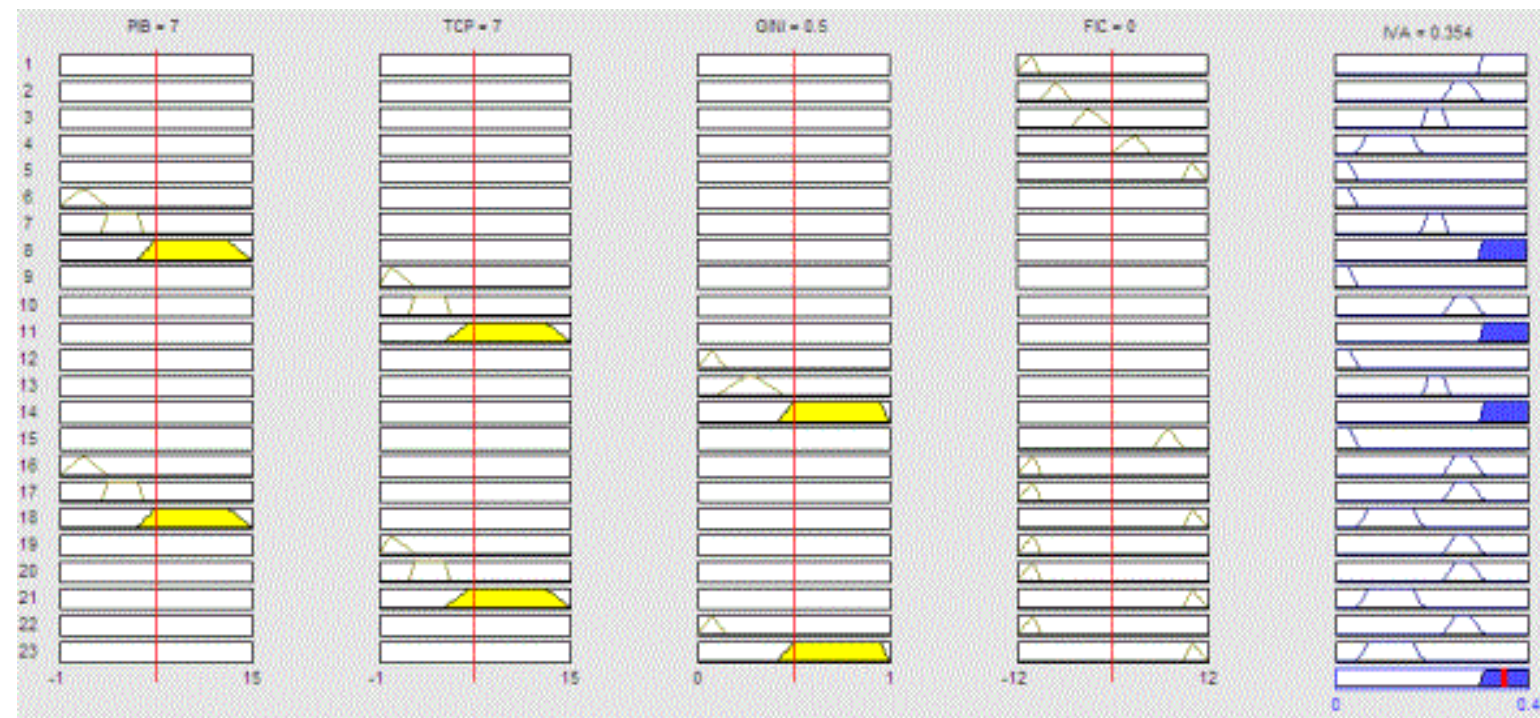

Figure 7: Aggregation process of the 23 rules of the fuzzy inference system of the EVI analysis.

\begin{tabular}{|l|l|l|l|l|l|}
\hline Study scenario & GDP & RPG & GINI & IF & Results \\
\hline Developed country (North American condition) & $8 \%$ & $1 \%$ & 0.15 & -1.92 & Medium High EVI=0.272 \\
\hline Developing country & $2 \%$ & $4 \%$ & 0.55 & -1.92 & Medium high EVI=0.271 \\
\hline Colombia 2007 & $3.50 \%$ & $2.50 \%$ & 0.58 & -1.92 & Medium high EVI $=0.297$ \\
\hline Transition country (e.g., Vietnam) & $10 \%$ & $2.00 \%$ & 0.38 & 1 & Medium high EVI $=0.269$ \\
\hline Colombia (expected conditions) & $10 \%$ & $4 \%$ & 0.55 & -7 & Medium high EVI $=0.321$ \\
\hline Developed country (Luxemburg) & $10 \%$ & $0 \%$ & 0.05 & 3 & Medium high EVI $=0.190$ \\
\hline Sierra Leona & $0 \%$ & $8 \%$ & 0.79 & -10 & Medium high EVI $=0.283$ \\
\hline
\end{tabular}

Table 1: Study scenarios for EVI analysis.

The proposed methodology can be extrapolated to other environments such as a microbasins and macro-projects, adjusting economic and environmental factors and variables, but surely involve cautious and critical exercise that demand highly qualified personnel, resources and time for an investigation the can come up with new and meaningful knowledge.

\section{References}

1. Edgar Ricardo MV (2010) Systemic model for environmental impact assessment at basin level.

2. Enrique Ongay D, Ambiental P, Conflictos DET (2006) Specialist in Environmental Planning and Integral Management of Natural Resources.

3. Ross TJ (2009) Fuzzy logic with engineering applications. John Wiley \& Sons.

4. Pouey NE, Vasello OA, Portapila MI (1994) Methodological aspects for the evaluation of the environmental impact in projects of urban sanitation. In Ingeniería ambiental para el desarrollo sostenible AIDIS p: 18.
5. Junior AC, Rohm SA (2014) Analysis of Environmental Fragility Using Multi-Criteria Analysis (MCE) For Integrated Landscape Assessment. J Urban Environ Eng 8: 28-37.

6. Acosta Barradas R (2012) Notas de Macroeconomía Avanzada. Modelo Clásico y Keynesiano. Doctorado en Finanzas Públicas, Facultad de Economía, Universidad Veracruzana, Xalapa, Ver., México.

7. Silva-Flores R, Pérez-Verdín G, Návar-Cháidez JDJ (2010) Valoración económica de los servicios ambientales hidrológicos 16: 31-49.

8. Pouey N, Monroy ER (2010) Nuevos Aportes para estimar el impacto ambiental a nivel de cuenca. Revista Ingenio Magno.

9. Pouey N, Monroy ER (2016) Nuevo Indicador de Valor Ambiental (IVA), para Inferir el Costo Del Estado Ambiental de una Cuenca. Cuadernos Del CURIHAM Revista De Estudios Sobre La Cuestión Hidroambiental 21: 11-17.

10. Bohórquez T, Orgay-Delhumeau E (1992) lnternational lending and resource development in Mexico: Can environmental quality be assured, Ecological Economics, Amsterdam pp 197-211. 